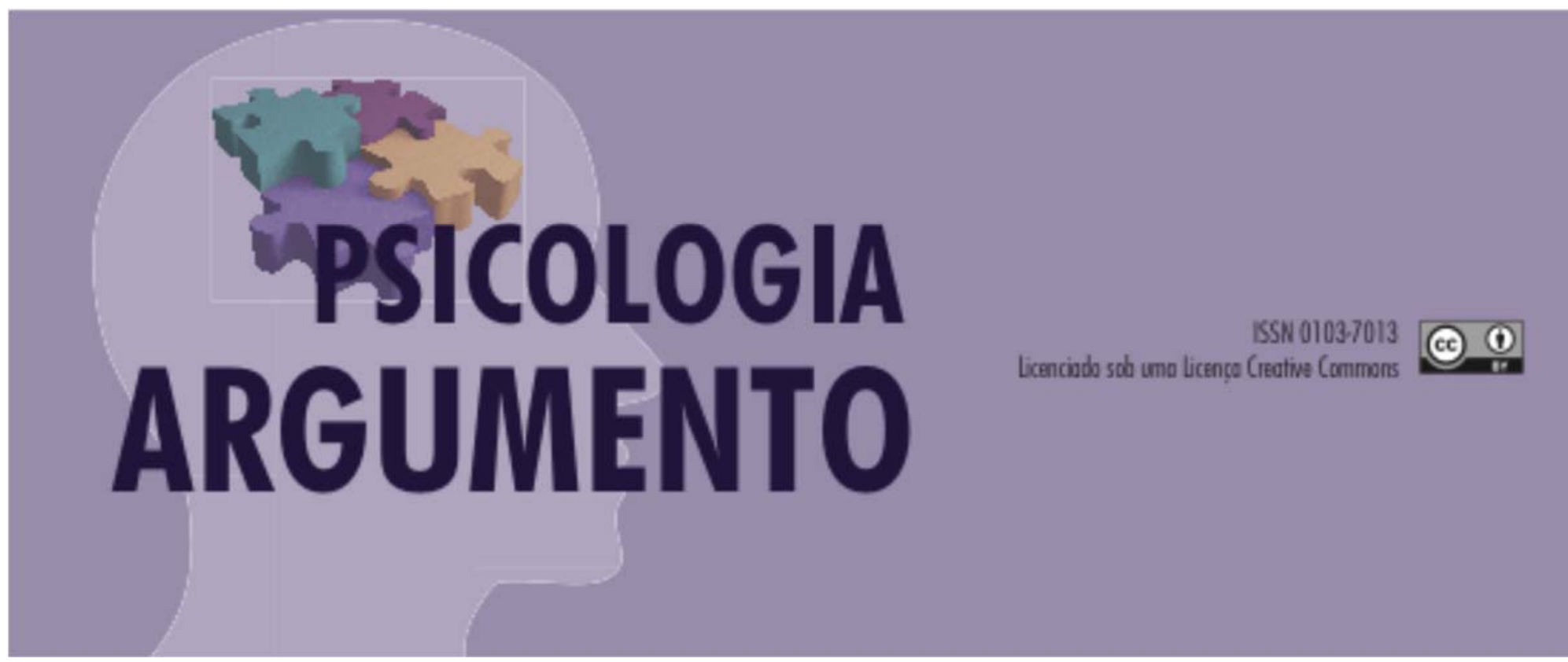

doi: http://dx.doi.org/10.7213/psicolargum.36.92.AO04

\title{
Análise dos laudos de psicólogos do judiciário nos casos de abuso sexual intrafamiliar.
}

Analysis of reports prepared by judiciary's psychologists in intrafamilial sexual abuse cases.

\begin{abstract}
Elaine Beatriz Ferreira de Souza Oshima ${ }^{[a]}$, Maria da Graça Saldanha Padilha ${ }^{[b]}$, Maria Cristina Antunes ${ }^{[c]}$

[a] Mestre em Psicologia pela Universidade Tuiuti do Paraná, elaine.s.oshima@fesppr.edu.br, Orcid: https://orcid.org/0000-0001-6859-2178
\end{abstract}

[b]Doutora em Psicologia pela UFSCAR, Docente da Universidade Tuiuti do Paraná, mgspadilha@gmail.com, https://orcid.org/0000-0003-2127-7570

[c]Doutora em Psicologia pela USP, Docente do Mestrado em Psicologia da Universidade Tuiuti do Paraná, mcrisantunes@uol.com.br, https://orcid.org/0000$\underline{0002-6767-518 X}$

\section{Resumo}

Essa pesquisa avaliou laudos elaborados por psicólogos do judiciário, nas demandas com alegações de abuso sexual intrafamiliar, sem a comprovação de conjunção carnal. Foram selecionadas 20 demandas, compostas por 8 ações de Destituição de Poder Familiar e 12 de Medidas de Proteção, as quais tramitavam perante a Vara de Infância e Juventude, de uma Comarca do sul do Brasil, integrada pela Defensoria Pública. Os autos foram categorizados da seguinte forma: gênero da vítima; idade da vítima; suposto abusador; breve relato dos fatos; oitiva da criança e adolescente pelo psicólogo do judiciário; realização de laudo psicológico antes da decisão liminar; quantidade de laudos psicológicos constantes nos autos; intervenção de perito nomeado e decisão judicial amparada no laudo. Os laudos psicológicos foram submetidos ao 
programa Iramuteq para análise qualitativa. Observou-se que o laudo realizado pelo Psicólogo do Judiciário é considerado prova pericial e serve de subsídio à decisão judicial, embora limitado, em sua grande maioria, à transcrição de forma técnica do relato dos envolvidos sobre o fato, obtidos tão somente pela entrevista.

Palavras-chave: abuso sexual intrafamiliar; laudo psicológico; prova pericial.

\begin{abstract}
This research evaluated the report prepared by judiciary's psychologists, in claims with allegations of intrafamilial sexual abuse, without the carnal conjunction's proof. A total of 20 lawsuits were selected, consisting of eight Family Power Destitution actions and 12 Protective Measures, which were filed before the Childhood and Youth Court of a Southern District of Brazil, made up of the Public Defender's Office. The records were categorized as follows: gender of the victim; age of the victim; alleged abuser; facts' brief report; child and adolescent testimony executed by the psychologist of the judiciary; performance of a psychological report before the preliminary decision; amount of psychological reports in the records; intervention of indicated expert and judicial decision covered by the report. The psychological reports were submitted to the Iramuteq program for qualitative analysis. It was observed that reports made by psychologists of the judiciary is considered expert evidence and serves as a subsidy to judicial decisions, although limited to the technical transcription of the report of those involved about the fact, obtained only by the interview, in most of the times.
\end{abstract}

Keywords: intrafamilial sexual abuse; psychological report; expert proof.

\title{
Resumen
}

Esta investigación evaluó el laudo elaborado por el psicólogo del judiciario, en las demandas con alegaciones de abuso sexual intrafamiliar, sin la comprobación de conjunción carnal. Se seleccionaron 20 demandas, compuestas por 8 acciones de Destitución de Poder Familiar y 12 de Medidas de Protección, las cuales tramitaban ante la Vara de Infancia y Juventud, de una Comarca del sur de Brasil, integrada por la Defensoría Pública. Los autos fueron categorizados de la siguiente forma: género de la víctima; edad de la víctima; presunto abusador; breve relato de los hechos; oitiva del niño y adolescente por el psicólogo del poder judicial; la realización de laudo psicológico antes de la decisión preliminar; cantidad de laudos psicológicos constantes en los autos; intervención de perito nombrado y decisión judicial amparada en el laudo. Los laudos psicológicos fueron sometidos al programa Iramuteq para análisis cualitativo. Se observó que el laudo realizado por el Psicólogo del Judiciario es considerado prueba pericial y sirve de subsidio a la decisión judicial, aunque limitado, en su gran mayoría, a la transcripción de forma técnica del relato de los involucrados sobre el hecho, obtenidos tan sólo por la entrevista.

Palabras clave abuso sexual intrafamiliar; laudo psicológico; prueba pericial.

\section{Introdução}

É cediço que o Direito e a Psicologia são ciências bem distintas e propõem a solução de conflitos de modo diverso. O Direito tem a função de organizar a sociedade e suas relações interpessoais, humanizando a justiça (Pelisoli, 2013). Nessa esteira, - Diploma Legal brasileiro intitulado Estatuto da Criança e do Adolescente (ECA) tornou obrigatória a presença de psicólogos e assistentes sociais nas Varas de Infância e Juventude e de Família, profissionais com a função de emitir parecer técnico, para ofertar ao magistrado subsídio para decisão (Brasil, 1990). 
Tal tarefa torna-se deveras desafiadora, principalmente em situações de abuso sexual sem comprovação de conjunção carnal, o que impõe ao psicólogo a utilização de técnicas para obter o relato fidedigno do ocorrido, reconhecer os elementos que evidenciam a ocorrência ou não do abuso sexual e observar os aspectos que possibilitam a permanência da criança junto à sua família. Fatores como a realização de avaliação psicológica restrita à entrevista, a falta de adoção de um protocolo adequado e o pouco conhecimento técnico do psicólogo para a identificação do abuso sexual infantil, podem resultar na produção de um laudo inconclusivo, o que promoverá discussões sobre a credibilidade do parecer psicológico que subsidiou a medida judicial. Por vezes, os processos judiciais registram uma série de evidências sobre um ponto controvertido, o que demanda de uma das partes a produção de provas para o convencimento do magistrado sobre a veracidade das alegações e da lesão do direito (Eloy, 2012).

No ordenamento brasileiro, a oitiva da criança e adolescente pode ser realizada por psicólogo do judiciário. Com o advento do Novo Código de Processo Civil (NCPC), é imprescindível a presença de um especialista para o acompanhamento do depoimento da criança e adolescente em situações de abuso ou alienação parental, nos termos do artigo 699 (Brasil, 2015; Wambier \& Wambier, 2015). É aconselhável a utilização de auxílio técnico para melhor compreensão dos fatos que sustentam o litígio, nas situações em que o conhecimento em questão supera o exigido do juiz e do homem de cultura média (Maranhão, 2005; Didier, 2015). O perito deve conduzir seu trabalho da forma que entenda ser a melhor, respeitados os limites da legalidade e da moralidade, para a apresentação de elementos técnicos necessários ao julgamento do caso pelo juiz, mediante apresentação do laudo (Didier, 2015).

A avaliação forense é uma perícia dotada de caráter investigativo e diagnóstico, sendo indispensável ao perito o conhecimento técnico e a experiência profissional (Dal Pizzol, 2017). Outrossim, a atividade pericial é considerada como a habilidade para identificar, relacionar e obter conclusões razoavelmente corretas dos dados, sem a inclusão de conhecidos vieses e ilusões sobre o abuso sexual infantil (FinnilãTuohimaa, Santtil, Sainio, Niemi \& Sandnabba, 2009; Jung, 2014; Freitas \& Javorski, 2015). Como instrumento científico, a perícia psicológica caracteriza-se como meio de prova, o que permite inserir aos autos informações técnicas fundamentais sobre o ponto controvertido, de tal forma que seja utilizado como subsídio em sua decisão (Perotti \& Siqueira, 2011; Rocha, Santos \& Serafim, 2016).

É certo, porém, que o conjunto probatório, por mais vasto que seja, não vincula obrigatoriamente a decisão do juiz, consoante o princípio da livre convicção, cabendo ao magistrado expor os motivos que o levaram a considerar ou não determinado elemento probatório (Marinoni, \& Arenhart, 2015). Em que pese o supracitado, uma pesquisa realizada no Tribunal de Justiça de Santa Catarina (Freitas e Freitas, 2003) demonstrou que grande parte das decisões judiciais em casos que envolvam criança e adolescente, são pautadas totalmente ou em parte nos laudos apresentados pelos peritos, sendo tal conhecimento determinante para o desfecho da demanda.

A avaliação psicológica equivale ao estudo psicossocial realizado pela equipe técnica do judiciário, composta por psicólogos e assistentes sociais e tem por objetivo assessorar os magistrados em suas decisões (Lima, 2003). Nesse contexto, o estudo 
psicossocial possui caráter interventivo, pautado na escuta, com maior foco na perspectiva social, sem enfatizar a psicopatologia (Ribeiro, Costa, Penso, Almeida \& Nogueira, 2010; Granjeiro \& Costa, 2010; Pelisoli, 2013). O estudo psicossocial tem grande importância na decisão judicial, pois traz ao magistrado respostas de questões sobre os maus tratos, a existência ou não de abuso sexual, a necessidade de concessão de medidas de proteção, entre outras (Pelisoli, 2013).

A maioria dos casos de abusos são intrafamiliares, o que torna mais difícil sua revelação e também mais doloroso para a vítima, pois em geral ela possui uma relação afetiva significativa com o agressor e por vezes não consegue diferenciar o cuidado ofertado por seu responsável como forma de abuso (Pelisoli, Gava e Dell'Aglio, 2011). Ao romper o silêncio, a vítima de abuso sexual intrafamiliar busca na intervenção estatal, a proteção de seus direitos. Geralmente, a trajetória da violência sexual tem início com o acionamento do Conselho Tutelar pelos demais órgãos da rede de proteção, tais como CREAS (Centro de Referência Especializado de Assistência Social), CRAS (Centro de Referência de Assistência Social), Escola, Posto de Saúde, disque 100, entre outros. Em regra, após a comunicação do fato, o Conselho Tutelar oficializa a denúncia ao Ministério Público, o qual ingressa na Vara de Infância e Juventude para a tomada de medidas cabíveis a cada caso (Faraj \& Siqueira, 2012). Nesse ínterim, a criança e adolescente são ouvidos mais de uma vez por profissionais diversos e, a cada nova entrevista, sofrem nova violência ao reviver os fatos (Dias, 2013).

Estudos apontam que as alegações de abuso sexual no contexto de separação parental são relativamente raros e por vezes decorrem das percepções errôneas sobre o problema das falsas alegações de abuso infantil e negligência (Trocmé \& Bala, 2005; Faller, 2015). A a alegação de abuso sexual, por vezes não é trazida nos autos de disputa de guarda como alegação inicial, sendo deflagrada a ocorrência desse tipo de violência no deslinde da demanda, por intermédio da avaliação psicológica (Gomide e Matos, 2016).

Diante da flagrante violação dos direitos e garantias da criança e adolescente, faz-se urgente a concessão imediata de medidas de proteção, de forma isolada ou cumulativamente, pelo magistrado da Vara de Infância e Juventude (Nucci, 2014). Para tanto, o ECA (Brasil, 1990), em seu artigo 101, elencou as seguintes medidas de proteção: encaminhamento aos pais ou responsável, mediante termo de responsabilidade; orientação, apoio e acompanhamento temporários; matrícula e frequência obrigatórias em estabelecimento oficial de ensino fundamental; inclusão em programa comunitário ou oficial de auxílio à família, à criança e ao adolescente; requisição de tratamento médico, psicológico ou psiquiátrico, em regime hospitalar ou ambulatorial; inclusão em programa oficial ou comunitário de auxílio, orientação e tratamento a alcoólatras e toxicômanos; acolhimento institucional; inclusão em programa de acolhimento familiar e a colocação em família substituta.

Em razão de condutas impróprias e abusivas dos pais, serão aplicadas a suspensão e destituição do poder familiar, como medida excepcional, aos casos em que não há possibilidade de aplicação de sanção menos gravosa (Seda, 2018). A suspensão do poder familiar é a restrição juridicamente imposta, de caráter temporário, direcionada para um dos pais ou ambos, aplicável a toda prole ou a um 
filho específico, em sua totalidade ou apenas em relação a determinadas funções parentais. Já, a destituição do poder familiar é a forma de cessação da função parental, de caráter compulsório e personalíssimo, aplicável em relação ao genitor que ensejou a medida, observado o melhor interesse da criança (Medina \& Carvalho, 2012).

Por fim, a oitiva da criança, independente da esfera jurídica, deverá ser conduzida por entrevistador treinado e capaz de evitar induções, ofertando a vítima de violência um ambiente adequado e acolhedor, a fim de obter um relato fidedigno sobre o ocorrido. Com efeito, a garantia de ações interdisciplinares efetivas ocorrerá com a capacitação dos profissionais que auxiliam o magistrado, bem como na maior valoração cientifica atribuída pelos operadores do direito aos laudos psicológicos (Azambuja, 2017; Padilha \& Vianna, 2016).

Dada a importância do laudo pericial, o objetivo dessa pesquisa foi avaliar qualitativamente o laudo elaborado pelo psicólogo do judiciário, enquanto prova pericial, nas demandas com alegações de abuso sexual intrafamiliar sem a comprovação de conjunção carnal.

\section{Método}

Trata-se de um estudo documental, de natureza quantitativa-qualitativa, no qual os dados foram coletados em processos judiciais cíveis que tramitam na Vara de Infância e Juventude de uma Comarca do Sul do Brasil, na qual a Defensoria Pública era parte integrante. A amostra foi composta por vinte processos, sendo doze de Medidas de Proteção e oito de Destituição de Poder Familiar, com alegações de abuso sexual intrafamiliar, sem a comprovação de conjunção carnal, propostos de 2009 a 2015, nos quais constam a produção de 50 (cinquenta) laudos elaborados pelos psicólogos do judiciário. Foram adotados como critérios de inclusão o acesso aos processos eletrônicos, com alegações de abuso sexual intrafamiliar, sem a comprovação de conjunção carnal.

\section{Procedimento}

$\mathrm{Na}$ etapa quantitativa, foi elaborado um relatório individual por processo eletrônico que compõe a amostra $(n=20)$, no qual constaram as seguintes informações: tipo da demanda; gênero da vítima; idade da vítima; suposto abusador; oitiva da criança e adolescente pelo psicólogo do judiciário; realização de laudo psicológico antes da decisão liminar; quantidade de laudos psicológicos constantes nos processos; intervenção de perito nomeado e decisão judicial vinculada ao laudo. Ao final, os dados constantes no relatório supramencionado foram processados eletronicamente no IBM SPSS, ocasião na qual foram calculadas as medidas de frequências das variáveis.

$\mathrm{Na}$ etapa posterior, os conteúdos dos laudos elaborados pelos psicólogos judiciários $(n=50)$, foram submetidos à análise qualitativa com o auxílio do software IRAMUTEQ (Interface de $R$ pour analyses Multidimensionnelles de Textes et de Questionnaires). O referido programa utiliza-se das unidades de contexto inicial (UCI), as quais são derivadas de acordo com a natureza dos dados obtidos. 
Os laudos elaborados pelos psicólogos do judiciário acostados em cada processo da amostra deram origem a uma $\mathrm{UCl}$, sendo o corpus dessa análise formado pelo conjunto das UCls. Após a definição das UCls pela pesquisadora, o programa Iramuteq divide o corpus em segmentos de textos, os quais contam em média com três linhas e são denominados como unidades de contexto elementar (UCEs).

Outrossim, o programa Iramuteq realizou a Classificação Hierárquica Descendente, a qual em sua primeira etapa classificou os segmentos de texto em função dos seus respectivos vocabulários, com a criação de um dicionário de formas reduzidas para compilar as palavras com raízes semelhantes (Polli, 2012). Na segunda etapa, o resultado foi obtido a partir de matrizes cruzando segmentos de textos e palavras (em repetidos testes do tipo chi-quadrado), aplicou-se o método de CHD e obteve-se uma classificação estável e definitiva (Reinert,1990). Obteve-se, na terceira etapa, a análise dos segmentos de texto que apresentaram ao mesmo tempo vocabulário semelhante entre si, e vocabulário diferente dos segmentos de texto das outras classes, ilustrado pelo dendrograma da CHD.

A referida ilustração demonstra as relações entre as classes, derivada da análise lexical dos textos, diferenciando os contextos (classes lexicais), os quais são caracterizados por vocabulário específico e por segmentos de textos que compartilharam do referido vocabulário (Camargo \& Justo, 2016). Posteriormente, foi realizada a análise de frequência do corpus, a qual é considerada uma análise lexical mais simples, pois agrupa as palavras e as organiza graficamente em função de sua frequência, com a produção da nuage de mots. A interpretação dos dados obtidos reflete a linguagem, os pensamentos, as opiniões e crenças das partes que compõem o processo e permite comparar produções diferentes em função de variáveis específicas (Lahlou, 2012).

Desse modo, a utilização do Iramuteq promoveu a análise dos laudos elaborados pelos psicólogos do judiciário, enquanto textos produzidos por diferentes indivíduos sobre um fato ocorrido em determinado grupo social, para verificar a compreensão do profissional sobre a ocorrência do abuso sexual intrafamiliar (Bauer \& Gaskell, 2015).

\section{Resultados}

Nos processos de medidas de proteção e destituição de poder familiar, que compõem a amostra do presente estudo, verificou-se que as idades das vítimas de abuso sexual intrafamiliar variaram de zero a 18 anos, assim dispostas: $15 \%$ das vítimas tinham de zero a cinco anos; $60 \%$ de seis a 12 anos; $20 \%$ de 13 a 15 anos e $5 \%$ das vítimas entre 16 e 18 anos. As vítimas do gênero feminino estiveram presentes em 18 processos, ou seja, $90 \%$ da amostra; somente em dois processos foram constatadas vítimas do gênero masculino, o que correspondeu a $10 \%$ da amostra.

Quanto ao suposto agressor, em $25 \%$ dos casos o pai foi considerado o suposto abusador; o padrasto foi apontado em $55 \%$ dos casos; em $5 \%$ dos casos o tio paterno foi identificado como abusador e $15 \%$ dos casos, o abusador foi apontado como terceiros (amigos e vizinhos dos responsáveis pela vítima). Não houve a identificação na amostra de suposto abusador do gênero feminino. 
A quantidade de oitivas das vítimas pelo psicólogo do judiciário e o número de laudos decorrentes variaram de uma a dez; em $75 \%$ dos casos as vítimas foram ouvidas para elaboração do laudo psicológico de uma a quatro vezes, já em $25 \%$ dos casos foram ouvidas de cinco a dez vezes. Isso quer dizer que em $25 \%$ dos processos foram encontrados de cinco a dez laudos psicológicos.

Observou-se, nos processos da amostra, que não houve a participação de perito nomeado em nenhum dos casos. Em contrapartida, em $100 \%$ dos casos a intervenção da Rede de proteção e Conselho Tutelar (instituições de proteção à criança) foi identificada. Consoante ao anteriormente exposto, foram considerados somente os laudos realizados pelo psicólogo do judiciário, sendo verificado que em $100 \%$ dos casos esses documentos foram utilizados como subsídio da decisão judicial.

Posteriormente, o conteúdo dos 50 laudos elaborados pelo psicólogo do judiciário, constantes nos processos da amostra $(n=20)$ foram submetidos a análise qualitativa, com o auxílio do programa de informática Iramuteq. Obteve-se, nesse estudo, o corpus composto por $327 \mathrm{UCls}$, com 1540 palavras, o que originou 6 (seis) classes da Classificação Hierárquica Descendente, as quais foram compostas por palavras com frequência igual ou maior a quatro e chi quadrado $\geq 3,75$.

O dendrograma (figura 1) ilustra a separação das classes, sendo composto por: a) o nome do corpus e a quantidade de textos retidos nele; b) o nome das classes e o número de textos que a compõem; c) a descrição das classes e das palavras que mais se associaram a ela, em função do chi quadrado $(\geq 3,75)$ e da frequência igual ou maior que quatro. Nota-se que o corpus sofreu uma primeira partição em dois subcorpora, colocando as classes 3, 2, 5 e 6 em oposição às classes 1 e 4.

Concernente as classes, após os resultados obtidos, estas foram assim nominadas: Classe 1: Prevenção enquanto medida - os meios jurídicos de proteção à criança e/ou adolescente vítima de abuso sexual intrafamiliar. Esta classe representa $21,2 \%$ do texto e foram selecionadas 27 palavras, com base na nota de corte de frequência e chi quadrado acima expostos; Classe 2: Foi assim que aconteceu - a importância da narrativa do abuso sexual pela criança e/ou adolescente. Foram escolhidas 25 palavras nesta classe, a qual é responsável por 23,1\% do texto; Classe 3: Entre os atos e os fatos - fatores indicativos do abuso sexual intrafamiliar. Aqui, 22 palavras foram selecionadas o que corresponde a $12,8 \%$ de todo o corpus; Classe 4: Conte-me mais sobre isso - o laudo psicológico como subsídio das decisões judiciais. Esta classe representa $15,3 \%$ do texto analisado, com a seleção de 27 palavras, com frequência igual ou maior a quatro e chi quadrado $\geq 3,75$; Classe 5 : Antes tarde do que nunca - a percepção do abuso sexual intrafamiliar por terceiros. Foram selecionadas 28 palavras na presente classe, a que corresponde $11,4 \%$ do corpus; Classe 6: Os indícios nos levam a crer - fatores de risco e a incidência de abuso sexual. Compõem esta classe 28 palavras e representa 16,3\% do corpus. 


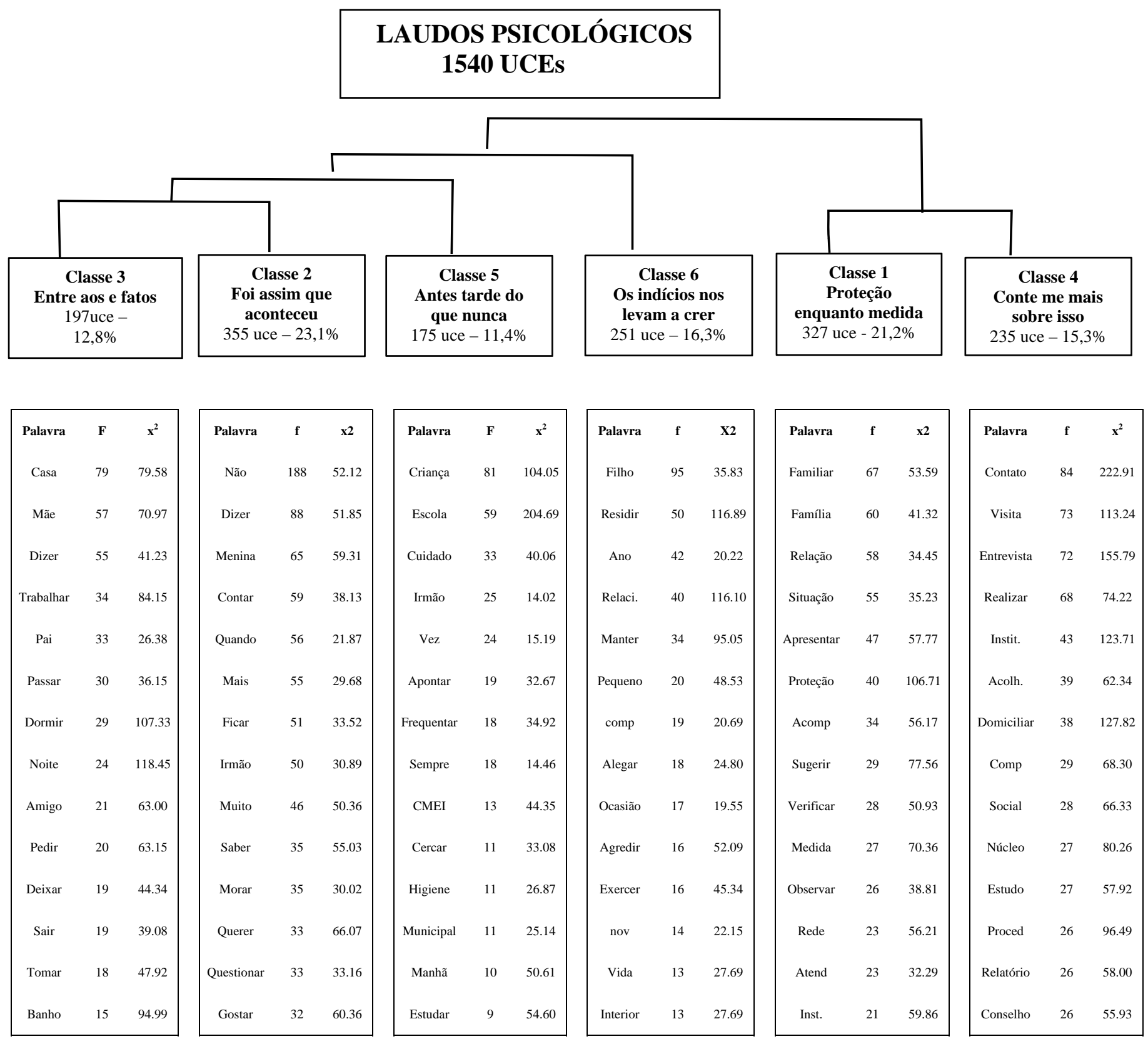

Figura 1 - Dendograma da análise descendente hierárquica dos laudos.

Por derradeiro, foi realizada a análise de frequência de palavras, como demonstra a figura 2, sendo que a palavra não obteve a maior frequência no corpus desse estudo $(n=50)$, com sua identificação por 566 vezes nas seis classes derivadas da classificação hierárquica descendente $(\mathrm{CHD})$. Ainda, a palavra genitora foi identificada 399 vezes; a palavra criança foi observada por 358 vezes e a palavra casa em 270 vezes. 


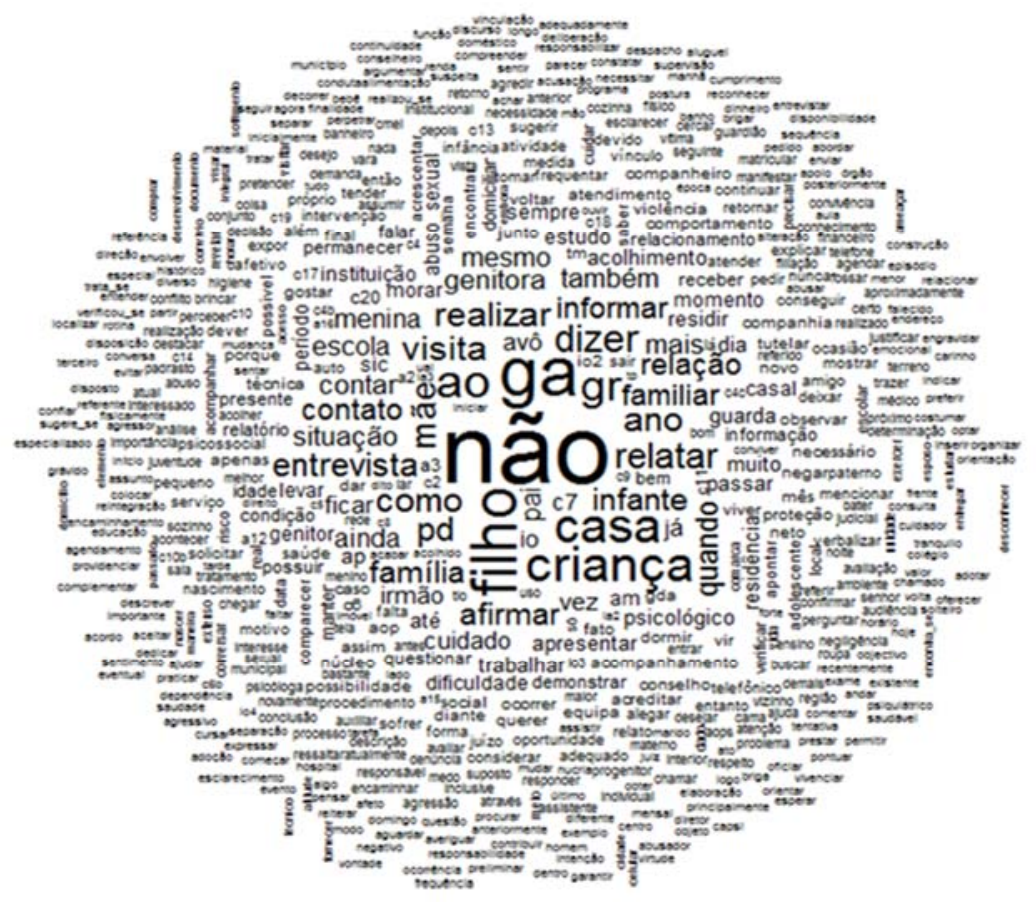

Figura 2 - Nuage de mots - Análise de frequência de palavras do corpus (n=50)

\section{Discussão}

Nesse estudo, os dados indicaram que, 15\% das vítimas tinham de 0 a 5 anos, $60 \%$ de 6 a 12 anos, 20\% tinham idade compreendida entre 13 a 15 anos e $5 \%$ de 16 a 18 anos. As crianças e adolescentes com idades compreendidas entre 6 a 15 anos configuram como vítimas em $80 \%$ dos casos. Os dados constantes no relatório do Instituto de Pesquisa Econômica Aplicada (IPEA) corroboram com os resultados acima expostos, pois em sua análise o referido órgão concluiu que em $50,7 \%$ dos casos de estupro, as vítimas possuíam até treze anos. Já, em 19,4\% dos casos a vítima eram adolescentes, na faixa etária de 14 a 17 anos (IPEA, 2014).

Verificou-se que $90 \%$ das vítimas eram do gênero feminino e $10 \%$ do gênero masculino. Os resultados apresentados assemelham-se com os constantes no relatório do IPEA (2014), o qual constatou que em $88,5 \%$ das vítimas são do gênero feminino e $11,5 \%$ do gênero masculino. Adiciona-se, ainda o estudo de Azambuja (2017), o qual analisou oitenta e duas demandas envolvendo violência sexual intrafamiliar contra crianças e adolescentes, ajuizados no Estado do Rio Grande do Sul entre 1999 e 2010 , e constatou que $86,59 \%$ dos casos eram de vítimas do gênero feminino, contra $13,41 \%$ do gênero masculino. 
No que tange aos abusadores, os resultados indicaram os padrastos em $55 \%$ dos casos, $25 \%$ eram os genitores, $5 \%$ tio paterno e $15 \%$ eram vizinhos ou amigos. A pesquisa do IPEA (2014) constatou que $24,1 \%$ dos agressores das crianças e adolescentes eram os próprios pais ou padrastos e 32,2\% eram amigos ou conhecidos da vítima. Verificou-se, ainda, que $70 \%$ dos estupros foram cometidos por parentes, namorados ou amigos/conhecidos da vítima, o que indica que o perpetrador está dentro de casa e que a violência nasce dentro dos lares. De igual modo, o estudo do IPEA (2014) demonstrou que $70 \%$ dos casos de estupro tem como vítimas crianças e adolescentes e em metade dos casos se configurou o histórico de estupros anteriores.

Consoante ao anteriormente exposto, o presente estudo se ateve a esfera cível ao analisar a intervenção judicial, nas demandas com alegações de abuso sexual intrafamiliar contra a criança e adolescente e a consequente tomada de medidas cabíveis. Obteve-se como resultado a concessão de 12 (doze) Medidas de Proteção e 8 (oito) Destituições de Poder Familiar. Revisando o conceito de medidas de proteção, observa-se em maior número, a determinação de acolhimento institucional, com o escopo de preservar a integridade física e psicológica da criança e do adolescente vítima de violência. Ainda, a aplicação de tal medida, permite ao magistrado a realização de estudo psicossocial e avaliação psicológica junto aos familiares e a investigação de interessados para a manutenção da criança e adolescente junto a família extensa. A intervenção e o consequente acompanhamento da Rede de Proteção foram constatados em todos os processos desse estudo, sendo que o Conselho Tutelar foi o grande articulador dos componentes da Rede, mediante a identificação de violação dos direitos das crianças e adolescentes. Deslandes e Campos (2015) conceituam Rede de Proteção como o conjunto formado pela sociedade civil, por meio de organismos governamentais e não governamentais, e tem por objetivo garantir os direitos com ações interventivas em situações de ameaça ou violação do direito da população infanto-juvenil.

Nessa pesquisa, os resultados demonstraram que as crianças e adolescentes foram ouvidas pelo psicólogo do judiciário, de uma a quatro vezes, em $75 \%$ dos casos. Já, em $25 \%$ dos casos as crianças e adolescentes desse estudo foram ouvidas de 5 a 10 vezes, para a elaboração de laudos. É pacificado entre os estudiosos do tema, que a criança e adolescente deve ser preservada, de tal modo que o seu questionamento sobre a violência sofrida seja feito na menor quantidade possível no decurso do processo (Pelisoli, 2013).

O presente estudo visou a interpretação do corpus originado a partir dos cinquenta laudos psicológicos, constantes nos vinte processos da amostra. Como anteriormente exposto, as classes apresentadas no dendrograma apontam diferentes perspectivas sobre os laudos psicológicos de abuso sexual intrafamiliar, sob o ponto de vista fático e suas consequências jurídicas.

No que tange a classe 1: Prevenção enquanto medida - os meios jurídicos de proteção à criança e adolescente vítima de abuso sexual intrafamiliar, observa-se que as palavras selecionadas estão ligadas essencialmente às formas de proteção da vítima de abuso sexual intrafamiliar. Destacam-se, na referida classe, as palavras família, relação, situação, apresentar, proteção, acompanhamento e medida, as quais apresentaram maior frequência. Nessa pesquisa, todas as demandas de abuso sexual 
foram noticiadas pela Rede de Proteção, sendo observado no corpus a intervenção do CREAS no atendimento realizado pela equipe técnica especializada e posterior avaliação social e psicológica dos envolvidos. Sabe-se que a revelação do abuso sexual é um momento crucial para a vítima, pois pode gerar revitimizações, caso os adultos não acreditem em seu relato e deixem de tomar as medidas protetivas cabíveis (Florentino, 2014). Assim, compete a rede de proteção ofertar o apoio social e afetivo para a vítima a fim de minimizar os danos do abuso sexual no momento em que consegue romper o segredo e revelar a violência (Brito \& Koller, 1999).

Foi assim que aconteceu - a importância da narrativa do abuso sexual pela criança e adolescente é o título da Classe 2 , que reteve $23,1 \%$ do texto, com a seleção de 25 palavras, tais como: não, dizer, contar, saber, morar, querer, questionar, gostar. Observa-se a utilização destas palavras pela vítima ao narrar o abuso sexual sofrido. Destarte, o presente trabalho buscou analisar as situações de abuso sexual intrafamiliar, enquanto espécie de violência que em regra possui só duas testemunhas, a vítima e o abusador (Gava, 2012). Em outras palavras, a dificuldade probatória em situações sem materialidade do delito impõe ao relato da vítima a condição de único meio de prova. Daí se pode afirmar, que a revelação da vítima sobre a ocorrência do abuso sexual intrafamiliar foi o que sustentou a concessão das medidas judiciais cabíveis. No Brasil, a trajetória da denúncia de abuso sexual intrafamiliar até a judicialização expõe a vítima à uma situação repetitiva, uma vez que será entrevistada por profissionais que compõem a Rede de Proteção, da Vara Criminal, da Infância e Juventude, os quais nem sempre dispõem de conhecimento técnico adequado (Williams, Padilha, Hackbarth, Blefari \& Peixoto, 2014; Padilha e Antunes, 2009). Em contrapartida, no âmbito internacional, a oitiva da criança e adolescente é realizada por meio de coleta de depoimentos por um circuito fechado de televisão e de videogravação ou sala de espelhos, em ambiente neutro e acolhedor, localizados na estrutura da polícia, tribunais, hospitais e até em Organizações não Governamentais. (Santos \& Gonçalves, 2009).

Denomina-se a Classe 3: Entre os atos e os fatos - fatores indicativos do abuso sexual intrafamiliar, que obteve a retenção de $12,8 \%$ do texto e 22 palavras selecionadas. Houve, na presente classe, maior frequência das palavras, casa, mãe, dizer, trabalhar, pai, passar, dormir, noite, amigo, sendo que estas palavras traduzem a realidade fática das vítimas de abuso sexual intrafamiliar. Segundo Pelisoli, Gava e Dell'Aglio (2011), a maioria dos casos de abusos são cometidos em ambiente intrafamiliar, o que torna ainda mais difícil sua revelação e mais doloroso para a vítima, visto que ela geralmente possui relações afetivas significativas com o abusador. Logo, o ambiente que deveria ser protetor da criança/adolescente se torna o ambiente vulnerável, que abusa e oprime, deixando as vítimas desprotegidas.

Na classe 4: Conte-me mais sobre isso - o laudo psicológico como subsídio das decisões judiciais, 15,3\% das palavras foram retidas do corpus, com a seleção de 27 palavras, sendo que as palavras contato, visita, entrevista, realizar, institucional, acolhimento, domiciliar, estudo, relatório apresentaram maior frequência e identificaram os elementos necessários para a elaboração do laudo psicológico. Segundo Pelisoli (2013), que o laudo psicológico deve ter clareza na linguagem e na forma estrutural, pois um documento mal elaborado acarretará equívoco na detecção 
da ocorrência ou não do abuso sexual, tendo em vista a complexidade desse fenômeno e a ausência de evidências físicas. Ainda, a necessidade da proteção da vítima é imperiosa, pois a judicialização de demandas como Medida de Proteção e Suspensão e Destituição de Poder Familiar são provas de que houve falha na defesa dos direitos fundamentais da criança e adolescente. No Brasil, a falta de adoção de instrumentos padronizados, adaptados e testados em nossa realidade expõem as vítimas a profissionais sem treinamento, que utilizam técnicas que traumatizam, induzem e inibem o relato sobre a violência (Williams et al.,2014). Já, no cenário internacional, há disponibilidade de vários protocolos de entrevistas forenses em situações de abuso sexual contra criança e adolescente, dentre os quais se destacam entrevista cognitiva revisada, Protocolo de Entrevista Investigativa NICHD, Protocolo da Corner House RATAC, Entrevista Forense da National Child Advocacy Center NCAC (Padilha \& Vianna, 2016; Goodman, Ogle, Troxel, Lawlwe \& Gordon, 2009).

Denominou-se a Classe 5: Antes tarde do que nunca - a percepção do abuso sexual intrafamiliar no ambiente escolar. Para tanto, foram selecionadas 28 palavras na presente classe, a qual apresentou $11,4 \%$ de retenção do texto. Destacam-se, as palavras criança, escola, cuidado, irmão, apontar, frequentar, estudar, cercar e afeto, as quais ilustram a importância do ambiente escolar para o reconhecimento da vítima de abuso sexual intrafamiliar. Os estudos apontam que as consequências da violência intrafamiliar são o baixo rendimento escolar, baixa concentração e atenção, dissociação e crenças distorcidas, tais como percepção de que é culpada pelo abuso, diferença em relação aos pares, desconfiança e percepção de inferioridade e inadequação, entre outros (Habigzang, Ramos \& Koller, 2011). Fica evidente a importância da participação da escola no acompanhamento das crianças e adolescentes expostos à situação de risco, com a função de identificar, denunciar e prevenir a ocorrência de abuso sexual. Mais que isso, a criança e adolescente passam grande parte do dia dentro da escola, ladeados por profissionais formados, os quais estão propensos a detectar casos suspeitos de abuso sexual e se tornarem veículos de prevenção primária, com atuação direta aos pais e aos alunos (Padilha \& Williams, 2011).

Por derradeiro, a Classe 6: Os indícios nos levam a crer - fatores de risco e a incidência de abuso sexual, obteve $16,3 \%$ de retenção do texto analisado e foram selecionadas 28 palavras, tais como, residir, relacionamento, manter, pequeno, engravidar, agredir, dentre as 28 selecionadas para compor o dendrograma. Nesse estudo, os dados obtidos demonstraram que o ambiente familiar das crianças e adolescentes não é propício ao desenvolvimento sadio, uma vez que não envolvem afeto, segurança, apoio, supervisão e estimulação. Tais famílias são caracterizadas pela literatura científica como de risco, pois proporcionam um ambiente inadequado aos seus, necessitando intervenção terapêutica para modificar as práticas educativas parentais e a ruptura no ciclo de desenvolvimento de comportamentos inadequados das crianças e adolescentes (Gomide, 2011; Carvalho \& Gomide, 2005; Pacheco \& Hutz, 2009; Borges \& Zingler, 2013). Todavia, não há como afirmar que a vulnerabilidade socioeconômica promove maior ocorrência de abuso sexual, haja vista que a amostra dessa pesquisa se ateve aos usuários da Defensoria Pública. De outra 
banda, a blindagem que o segredo de justiça reveste nestas demandas, impedem a realização de pesquisas em classes sociais diversas.

A figura 2 denominada nuage de mots representa a análise de frequência, com o objetivo agrupar e organizar graficamente as palavras do texto para a identificação das palavras-chave de um corpus. No presente trabalho, evidencia-se a palavra não ao centro ladeada pelas palavras filho, criança, casa, entrevista, sendo a palavra não a que obteve maior frequência, e se fez presente nos laudos analisados, em todas as classes identificadas, como será demonstrado. Na análise de frequência do corpus $(n=50)$ palavra não foi identificada 566 vezes nas seis classes derivadas da Classificação Hierárquica Descendente. Observou-se, ainda, que a palavra genitora foi identificada 399 vezes; a palavra criança foi observada por 358 vezes e a palavra casa em 270 vezes. Qual é o significado da palavra não nesse estudo?

Em verdade, a intervenção judicial em situações de negligência e todos os tipos de violência contra a criança e adolescente é apenas preventiva, garantidora do direito de quem já é por si só excluído, os tantos nãos de suas falas podem refletir o abandono, violência, falta de afeto e proteção. Infelizmente, a maior vítima é a criança e o adolescente, pois a supressão de seus direitos influencia o seu destino e ameaça sua felicidade, principalmente, nas situações de acolhimento institucional (Bastos, 2011).

\section{Conclusão}

A busca pela verdade é o que move o processo judicial e para os operadores do direito somente a verdade promoverá um julgamento mais justo. Porém, deve se considerar que as verdades trazidas pelas partes aos autos estão revestidas de subjetividade, principalmente, sobre o que é certo ou errado nas condutas dos litigantes em situações de violência sexual intrafamiliar. Soma-se, ainda, a dificuldade em precisar a ocorrência de violência sexual, quando não há evidências físicas que sustentem as alegações, para promover o afastamento entre a vítima e seu perpetrador.

Conforme os dados apresentados nesse trabalho, evidenciou-se que os psicólogos do judiciário e da rede de proteção são os primeiros a ter contato com a vítima, e por vezes não possuem técnica adequada às situações de abuso sexual, o que expõe a criança e adolescente a uma série de repetições de seu relato. Para tanto, o treinamento dos referidos profissionais é medida urgente, para promover um reconhecimento das situações de risco com maior celeridade e precisão, de tal modo a subsidiar a aplicação de medidas de proteção, acolhimento institucional e colocação em família substituta nas modalidades guarda ou adoção. Sugere-se, ainda, uma padronização nas avaliações forenses em situações de abuso sexual, o que há muito ocorre no cenário internacional. Sem dúvidas, a adoção de um protocolo acarretaria uma amostra definida, o que promoveria estudos mais específicos sobre a oitiva da criança por profissional habilitado e o conteúdo do relato, minimizando os danos aos maiores interessados. 


\section{Referências}

Ataide Júnior, V. P. (2009). Destituição de Poder Familiar. Curitiba: Juruá.

Azambuja, M. R. F. (2017). Inquirição da criança vítima de violência sexual: proteção ou violação de direitos. Porto Alegre: Livraria do Advogado.

Bastos, M. S. (2011). Da inclusão das minorias e dos grupos vulneráveis: uma vertente eficaz e necessária para a continuidade da ordem jurídica constitucional. Revista Brasileira de Direito Constitucional, n. 18. jul.dez.

http://www.esdc.com.br/seer/index.php/rbdc/article/view/258/251

Bauer, M. W. \& Gaskell. G. (2015). Pesquisa Qualitativa com Texto, Imagem e Som um manual prático. Rio de Janeiro: Editora Vozes.

Borges, J. L. \& Zingler, V.T. (2013). Fatores de risco e de proteção em adolescentes vítimas de abuso sexual. Psicologia em Estudo, vol.18, n.3, pp.453-463. http://dx.doi.org/10.1590/S1413-73722013000300007

Brasil. (1990). Lei 8069/90. Estatuto da Criança e do Adolescente. http://www.planalto.gov.br/ccivil 03/leis/L8069.htm

Brasil. (2015) Lei 13.105/15. Novo Código de Processo Civil. http://www.planalto.gov.br/ccivil 03/ ato2015-2018/2015/lei/l13105.htm

Brito, R. C.; Koller, S. H. (1999). Desenvolvimento humano e redes de apoio social e afetivo. Em: Carvalho, A. M. (org.) O mundo social da criança: natureza e cultura em ação. São Paulo: Casa do Psicólogo.

Camargo, B. V., \& Justo, A. M. (2016). Tutorial para uso do software IRAMUTEQ. Disponível

em http://www.iramuteq.org/documentation/fichiers/Tutorial\%20IRaMuTeQ\%20em\%20p ortugues 17.03.2016.pdf

Carvalho, M. C. N \& Gomide, P. I. C. (2005). Práticas educativas parentais em famílias de adolescentes em conflito com a lei. Estudos de Psicologia. Campinas, vol.22, n.3, 263-275. http://dx.doi.org/10.1590/S0103-166X2005000300005

Dal Pizzol, A. (2017) Perícia psicológica e social na esfera Judicial. Em Rovinski, S. L. $\mathrm{R}$ e Cruz, R. M (org.) Psicologia Jurídica- Perspectivas teóricas e processos de intervenção. Kindle ebook. São Paulo: Vetor.

Deslandes, S. F. \& Campos, D.S. (2015). A ótica dos conselheiros tutelares sobre a ação da rede para a garantia da proteção integral a crianças e adolescentes em situação de violência sexual. Ciência \& Saúde Coletiva. 20(7) , 2173-2182. http://dx.doi.org/10.1590/1413-81232015207.13812014

Dias, M. B. (2013). Incesto e Alienação parental. São Paulo: Editora Revista dos Tribunais. 
Didier Jr., F. (2015). Curso de Direito processual civil: teoria da prova, direito probatório, ações probatórias, precedente, coisa julgada e antecipação dos efeitos da tutela. vol. 2. Salvador: Editora Jus Podivm.

Eloy, C. (2012). A Credibilidade do testemunho da criança vítima de abuso sexual no contexto judiciário. Psicologia: Ciência e Profissão, 2012, 32(1), 234-249. http://dx.doi.org/10.1590/S1414-98932012000100017

Faller, K. C. (2015). Forty Years of Forensic - Interviewing of Children Suspected of Sexual Abuse, 1974-2014: Historical Benchmarks. Social Sciences, 4, 34-65. https://doi.org/10.3390/socsci4010034

Finnilã- Tuohimaa, K., Santtila, P., Sainio, M., Niemi, P. \& Sandnabba, K. (2009). Expert judgment in cases of alleged child sexual abuse: Clinician's sensitivity to suggestive influences, pre-existing beliefs and base rates estimates. Scandinavian Journal of Psycology, 50, 129-142. https://doi.org/10.1111/j.1467-9450.2008.00687.x

Florentino, B. R. B. F. (2014). Abuso sexual, crianças e adolescentes: reflexões para o psicólogo que trabalha no CREAS. Fractal, Revista de Psicologia, 26 (1), 59-70. http://dx.doi.org/10.1590/S1984-02922014000100006

Freitas, D. P. e Freitas, K. B. M. (2003). Perícia Social: o assistente social e a perícia no judiciário. Revista da Ordem de Santa Catarina. 125. Disponível em: http://www.apase.org.br/13002-apraticadoestudo.htm

Freitas, D. P, Javorski, J. (2015). Perícia Social e Psicológica no direito de família. Florianópolis: Vox legem.

Gava, L. L. (2012). Perícia Psicológica no Contexto Criminal em casos de suspeita de abuso sexual infantojuvenil. (Tese de Doutorado). Universidade Federal do Rio Grande do Sul. Instituto de Psicologia. Programa de Pós-Graduação em Psicologia. Disponível em: http://www.lume.ufrgs.br/handle/10183/7003

Gomide, P. I. C. (2011). Psicologia Forense e suas conexões com as diversas áreas da Psicologia. Em Gondim, S. M. G \& Chaves, A. M. (org.). Práticas e saberes psicológicos e suas conexões, pp. 245-266. Salvador: UFBA.

Gomide, P. I. C. \& Matos, A. C. H. (2016). Diálogos interdisciplinares acerca da Alienação Parental. Em Gomide, P. I. C. (org.). Introdução à Psicologia Forense. Curitiba, Juruá Editora.

Goodman, G. S., Ogle, C. M., Troxel, N., Lawler, M. J., \& Gordon, I. M. (2009). Crianças vítimas no sistema judiciário: como garantir a precisão do testemunho e evitar a revitimização. Em Santos, B. R., \& Gonçalves, I. B. (coord.) Depoimento sem medo(?): culturas e práticas não revitimizantes: uma cartografia das experiências de tomada de depoimentos especial de crianças e adolescentes. São Paulo: Childhood Brasil. 
Granjeiro, I. A. C. L. \& Costa, L. F. (2010). A interdisciplinaridade entre Direito e Psicologia no conflito familiar violento. Revista de Informação Legislativa, 185, $195-$ 209. Disponível em: http://www2.senado.leg.br/bdsf/item/id/198667

Habigzang, L. F., Ramos, M. S. \& Koller, S.H. (2011). A Revelação de Abuso Sexual: As Medidas Adotadas pela Rede de Apoio. Psicologia: Teoria e Pesquisa, 27 (4), pp. 467-473. Recuperado a partir de http://www.scielo.br/pdf/ptp/v27n4/10.pdf

Instituto de Pesquisa Econômica Aplicada - IPEA (2014). Estupro no Brasil: uma radiografia segundo os dados da saúde. Disponível em: http://www.ipea.gov.br/portal/images/stories/PDFs/nota tecnica/140327 notatecnica diest11.pdf

Jung, F. H. (2014). Avaliação Psicológica Pericial: Áreas e Instrumentos. Revista Especialize On-line, $\mathrm{n}^{\circ}$ 008(01), 1-17. Disponível em:

http:// www.ipog.edu.br/download-arquivo-site.sp?...psicologica-pericial-areas

Lahlou, S. (2012). Text Mining Methods: An answer to Chartier and Meunier. Papers on Social Representations, 20 (38), 1-7. Disponível em: http://www.psych.Ise.ac.uk/psr/psr2011/20 39.pdf

Lima, H. G. D. (2003). Apresentação. Em H. G. D. Lima (coord.) Construindo caminhos para a intervenção psicossocial no contexto da Justiça. Brasília: TJDFT

Lyon, T. D., Lamb, M. E., \& Myers, J. (2009). Authors' response to Vieth: Legal and psychological support for the NICHD Interviewing Protocol. Child Abuse \& Neglect, 7174 https://doi.org/10.1016/j.chiabu.2009.02.002

Maranhão, O. R. (2005). Curso Básico de Medicina legal. São Paulo: Malheiros Editores.

Marinoni, L. G.\& Arenhart, S.C. (2015). Prova e Convicção - de acordo com o CPC de 2015. São Paulo: Revista dos Tribunais.

Medina, R.V. e Carvalho, M. C. N. (2012). Destituição do Poder Familiar: mãe que perderam o direito de serem mães. Em Carvalho, M. C. N. (coord.). Psicologia e Justiça- Infância, Adolescência e Família. Curitiba: Juruá.

Nucci, G. S. N. (2014). Estatuto da criança e do adolescente comentado - Em busca da Constituição Federal das crianças e adolescentes. Rio de Janeiro: Forense.

Pacheco, J. T. B \& Hutz, C. S. (2009). Variáveis Familiares Preditoras do Comportamento Antissocial em Adolescentes Autores de Atos Infracionais. Psicologia: Teoria e Pesquisa, 25 (2), 213-219 http://dx.doi.org/10.1590/S0102$\underline{37722009000200009}$

Padilha, M.G.S.; Antunes, M.C. (2009) Considerações sobre o Depoimento sem Dano em casos de abuso sexual contra crianças e adolescentes. Em: Williams, L.C.A. \& 
Araújo, E.A.C.. (Org.). Prevenção do Abuso Sexual Infantil: Um enfoque interdisciplinar. Curitiba: Juruá.

Padilha, M. G. S. \& Williams, L. C. A (2011). Intervenção escolar na prevenção do abuso sexual com estudantes pré-adolescentes e adolescentes. Em Williams, L. C. A. \& Araújo, E. A. C. (org.) Prevenção do abuso sexual infantil: Um enfoque interdisciplinar. Curitiba: Juruá Editora.

Padilha, M. G. S. e Vianna $F^{\circ}$, I. X. (2016). Abuso sexual: a violência sexual contra vulneráveis. Em Gomide, P. I. C. (org.) Introdução à Psicologia Forense. Curitiba: Juruá Editora.

Pelisoli, C. L. (2013). Psicologia e as relações com a justiça: práticas, conhecimento e tomada de decisão em situações de abuso sexual. (Tese de Doutorado). Universidade Federal do Rio Grande do Sul.

http:// www.lume.ufrgs.br > ... > Ciências Humanas > Psicologia.

Pelisoli, C., Gava, L. L. \& Dell'Aglio, D. D. (2011). Psicologia jurídica e tomada de decisão em situações envolvendo abuso sexual infantil. Psico USF, 16, 327-338.

http://dx.doi.org/10.1590/S1413-82712011000300009

Perotti, D. C. O. \& Siqueira, I. L. S. M. (2011) A perícia psicológica e seu papel como prova nos processos judiciais. Em: Carvalho, M. C. N., Fontoura, T. \& Miranda, V. R. (org.). Psicologia Jurídica - Temas de Aplicação. Curitiba: Juruá.

Polli, G. M. (2012). Representações sociais do meio ambiente e da água na mudança de paradigmas ambientais. (Tese de Doutorado). Universidade Federal de Santa Catarina. https://repositorio.ufsc.br/bitstream/handle/123456789/.../315366.pdf.

Reinert, M. (1990). Alceste, une méthodologie d'analyse des données textuelles et une application: Aurelia de Gerard de Nerval. Bulletin de Methodologie Sociologique, v.26, p.24-54. http://www.iramuteq.org/documentation/fichiers/tutoriel-en-portugais

Ribeiro, M. A., Costa, L. F., Penso, M. A., Almeida, T. M. \& Nogueira, H. F. (2010) O grupo multifamiliar em parceria com a ação psicossocial forense. Interação em Psicologia.14(1), p. 73-82. http://dx.doi.org/10.5380/psi.v14i1.8586

Rocha, G. M., Santos, W. S. \& Serafim, A. P. (2016). Avaliação Forense: Definição e Especificidades de uma contribuição da Psicologia para o Direito. Em Gomide, P. I. C (org.). Introdução à Psicologia Forense. Curitiba: Juruá.

Santos, B. R., \& Gonçalves, I. B. (2009). Depoimento sem medo: Culturas e práticas não revitimizantes - uma cartografia das experiências de tomada de depoimento especial de crianças e adolescentes. São Paulo: Childhood Brasil.

Seda, E. (2018). Medidas de Proteção. Em Cury. M. (coord.) Estatuto da Criança e do Adolescente - Comentado. São Paulo: Malheiros Editores. 
Trocmé, N. \& Bala. N. (2005) False allegations of abuse and neglect when parents separate. Child Abuse and Neglect, 29, 1333-1345. https://doi.org/10.1016/j.chiabu.2004.06.016

Wambier, T. A. A e Wambier, L. R. (2015). Novo Código de Processo Civil comparado: artigo por artigo. (coord.) São Paulo: Revista dos Tribunais.

Williams, L.C.A., Padilha, M.G.S., Hackbarth, C., Blefari, C.Z. \& Peixoto, C. E. (2014). Investigação de suspeita de abuso sexual infantojuvenil: O Protocolo NICHD. Temas em Psicologia, vol.22, nº 2, 1-19. http://dx.doi.org/10.9788/TP2014.2-12 